\title{
Design and Construction of a Spiral Heat Exchanger
}

\author{
Jamshid Khorshidi*, Salman Heidari \\ Department of Engineering, Hormozgan University, Bandar Abbas, Iran \\ Email: "jkhorshidi@yahoo.com
}

Received 28 February 2016; accepted 24 April 2016; published 27 April 2016

Copyright (C) 2016 by authors and Scientific Research Publishing Inc.

This work is licensed under the Creative Commons Attribution International License (CC BY). http://creativecommons.org/licenses/by/4.0/

(c) (i) Open Access

\begin{abstract}
In this article, the performance and applications of a Spiral Plate Heat Exchanger are demonstrated. Also, governing equation of heat transfer phenomena in such heat exchangers is discussed. Regarding the governing equations, a LAB-sized model of this type of heat exchanger was designed and constructed. Galvanized Iron sheets were used as the heat transfer surfaces. Two Galvanized Iron sheets were rolled together around a central core and, as a result, two separated channels were made. Also, a predesign simulation of the heat exchanger was done using the Fluent software to predict the performance of the heat exchanger. First the geometry was made using Gambit software environment then the model was analyzed through Fluent. Because of less fouling, easier cleaning and high heat transfer coefficient, Spiral Heat Exchanger is a good alternative to the other types of heat exchangers, especially when it's going to handle high fouling flows or highly viscous fluids. Low fouling rate of the heat exchanger, reduces the need of cleaning and therefore the out of service will be decreased. In the constructed heat exchanger, Nusselt number increases as the mass flow rate increases. Average Nusselt number is about 100 that is very good.
\end{abstract}

\section{Keywords}

Heat Exchanger, Spiral, Numerical Modelling, Design, Construction

\section{Introduction}

Heat exchangers are approximately the most used parts in chemical processes and can be seen in almost all industrial units. These are the tools providing the possibilities for heat transfer between two or more fluids. Heat transfer can be done in arrangements of liquid-liquid, liquid-gas and gas-gas. Heat exchangers are used in order to cool a hot fluid or to warm a cold fluid or both together. Heat exchangers are used in a wide variety of appli-

${ }^{*}$ Corresponding author. 
cations such as in power plants, refineries, petrochemical industries, process industries, food and drug industries, heating and air conditioning. Spiral heat exchangers have got especial usage in handling high viscous fluids, high solid content flows and two-phase solid-liquid flows.

Cleaning after fouling is one of the most expensive issues related to heat exchangers that lead to waste the time and money. As an example, the costs of fouling in the USA industries reach up to 5 billion dollars a year.

Among different types of heat exchangers that are used for cooling and heating the fluids in industries, Spiral Plate Heat Exchanger (SPHE) has an especial place. As shown in Figure 1, a SPHE consists of two sheets that were rolled around a central rod and therefore two separated concentric channels are made.

The ends of the channels are sealed through welding. There are two possibilities to seal the sides of the heat exchanger: using bolts and gaskets to fasten the covering sheets to the heat exchanger or welding the covering sheets to the heat exchanger. Both have their own advantages and disadvantages. For the case of bolts and gaskets one can open the heat exchanger easier and do the maintenance with more comfort. But the sealing is more complicated and working parameters are restricted to those of the gasket. On one hand, welding will extend working parameter possibilities. On the other hand, it makes the maintenance more difficult. Anyway, we decided to use welding approach.

Each of the concurrent and countercurrent trends of flows is available. Almost always the hot fluid enters the heat exchanger in the center and quits at the periphery. Cold fluid can enter either from the center or from the periphery, and therefore, this choice will lead to concurrent or countercurrent flows, respectively. It is obvious that countercurrent arrangement has better heat transfer performance.

Figure 1 shows the most common arrangement type for flows. Distance between heat transfer surfaces can be chosen from 5 to $25 \mathrm{~mm}$ to optimize the velocity and heat transfer behavior. Commonly, heat capacity and heat transfer surface area of this type of heat exchanger are up to $900 \mathrm{Kw}$ and $500 \mathrm{~m}^{2}$, respectively for one unit. For higher capacities that are especially required for cellulosic and coke industries, parallel and series arrangements can be used. SPHE can work under pressure up to 15 bar and temperature up to 450 degrees Celsius.

One passaged path of the flow, spiral shape of the path, and existence of studs among the channels will lead to turbulent flows even at velocities lower than anticipated. This and spiral nature of the flow cause permanent impact of the fluid particles to the heat transfer surfaces, and so, prevent the fouling. As fouling increases, the local velocity of fluid increases and this higher speed will remove the fouling. It must be mentioned here that for the heat exchangers that have more than one passage to flow through, such as for the case of shell and tube heat exchanger, when fouling occurs in one passage, flow will go through another passage and the speed in first passage decreases and the fouling will grow even more.

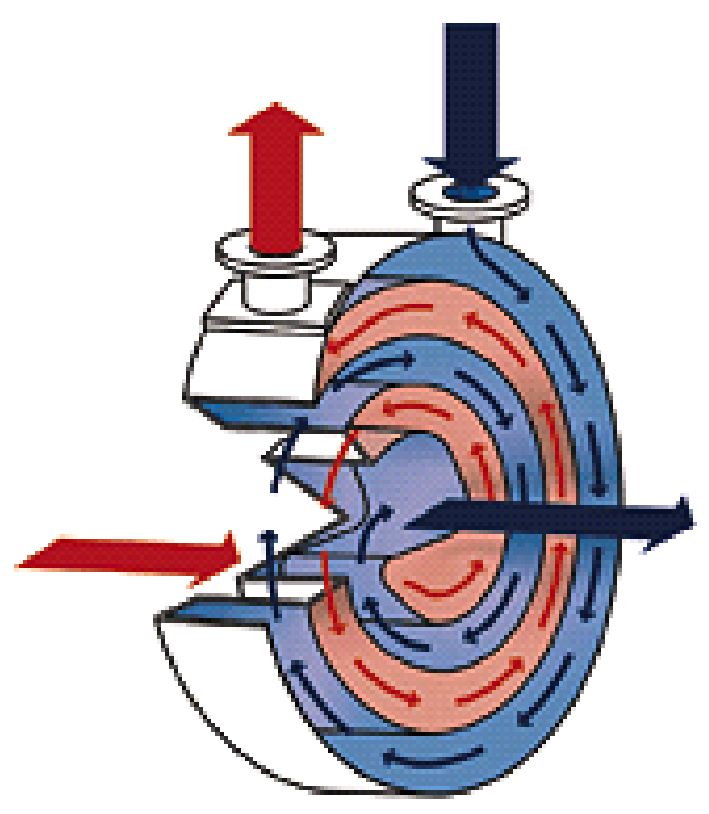

Figure 1. Spiral plate heat exchanger. 


\section{Literature Review}

In the past years some efforts have been done to use Spiral Heat Exchangers and to simulate the flow in them. Oil extraction system pipes were studied by G. E. Kondhalkar and V. N. Kapatkat. They found out that spiral tube could be used to reduce the costs [1]. Thermal performance and pressure drop of the helical-coil heat exchangers were considered by P. Naphon. This work showed that mass flow rate of both the hot and cold fluids flows had considerable effects on the heat exchanger performance [2]. P. M. Deshpande and S. Dawande studied hydrodynamics of horizontal spiral coil tube. Their effort led to the result that the transverse vibrations of the conical coiled tubes have noticeable effect on the entrance tube vibration frequency [3]. M. S. Tandale and S. M. Joshi designed a spiral heat exchanger to recover the waste heat from producer gas. They realized that several forces (viscous, buoyancy, and centrifugal) influenced the flow in spiral tubes [4]. Mathematical analysis of the transverse vibration of conical spiral tube was done by Y. Ke et al. Experiments showed that the difference between the heat transfer coefficients that were calculated by experimental procedure and by analytical approach was about $12 \%$ [5]. M. P. Nueza et al. studied the design approach for the spiral heat exchangers. They made it clear that the heat transfer rate of the spiral heat exchanger is more than that of the other types of heat exchangers [6]. Design of spiral tube heat exchangers was studied by P. E. Minton. This work led to some relations usable for designing heat exchangers [7]. Y. Mori and W. Nakayama worked on forced convective heat transfer in curved pipes for high dean numbers. Flow and temperature fields were studied theoretically and experimentally. They thought that the flow was divided into two parts: a main central flow and a thin boundary layer near the walls [8]. C. E. Kalb and J. D. Seader discussed heat and mass transfer phenomena for viscous flow in curved circular pipes. They did numerical analysis for uniform wall heat flux, while uniform peripheral temperature was supposed, for the Dean number range of 1 - 1200 and Prandtl number range of 0.005 - 1500 and the curvature ratios of 10 - 100 for developed velocity and temperature fields. They found out that the curvature ratio parameter had little effect on the Nusselt number no matter what the Prandtl number was [9].

\section{Exchanger Design}

The design of heat exchangers is done in two steps. First, thermal and fluid dynamical design and then mechanical design. Thermal and fluid dynamical design is the main and substantial step to heat exchanger design. This calculates the required heat transfer surface and pressure drop for the heat exchanger. The goal of mechanical design is to have a heat exchanger able to tolerate working conditions. Actually, this step is going to determine physical properties and shape of the heat exchanger.

\subsection{Thermal Design}

During heat exchanger design often overall heat transfer coefficient is used that connects the rate of heat transfer to the temperature difference of the system. Actually, all the resistances to the heat transfer including that of cold fluid film, wall thickness, hot fluid film, and fouling resistances in both sides are compacted in one coefficient. Finally, the relation for heat transfer is as relation (1).

$$
Q=U * A * F * \Delta T_{L M T D}
$$

where: $A$ is the heat transfer surface area, $F$ is a correction coefficient, $\Delta T_{L M T D}$ is the mean logarithmic temperature difference, and $U$ is the overall heat transfer coefficient. $U$ is defined as below:

$$
U=\frac{1}{\frac{1}{h_{h}}+\frac{t_{w}}{k_{w}}+\frac{1}{h_{c}}+r_{i}+r_{o}}
$$

where: $h_{h}$ and $h_{c}$ are heat transfer coefficients of the hot and cold fluids, $k_{w}$ is the conductivity of wall (heat transfer surface), $r_{i}$ and $r_{o}$ are the fouling resistances of both sides, and $t_{w}$ is the wall thickness.

Some experimental relations are available to calculate $h_{h}$ and $h_{c}$ for heat exchanger [1]:

For radial laminar flow:

$$
h=1.86 * C * G *[R e]^{-2 / 3}\left[\frac{L}{D_{e}}\right]^{-1 / 3}\left[\frac{z_{f}}{z_{b}}\right]^{-0.14}
$$


and for radial turbulent flow:

$$
h=\left(1+3.54 * \frac{D_{e}}{D_{h}}\right) * 0.023 * C * G *[R e]^{-0.2} *[\operatorname{Pr}]^{-2 / 3}
$$

where: $D_{e}$ is the equivalent diameter (ft), $D_{h}$ is the spiral diameter (ft), $L$ is the length of each heat transfer surface (ft), $z$ is viscosity (cp), $c$ refers to specific heat capacity $\left(\frac{\mathrm{Btu}}{\mathrm{lb}^{\circ} \mathrm{F}}\right), G$ is mass flow rate $\left(\frac{\mathrm{lb}}{\mathrm{hr} \cdot \mathrm{ft}^{2}}\right), h$ is heat transfer coefficient $\left(\frac{\mathrm{lb}}{\mathrm{lb} \cdot \mathrm{hr} \cdot \mathrm{ft}^{2}}\right)$, Re is the replacement for Reynolds Number, and $\operatorname{Pr}$ denotes Prandtl Number.

$R e$ is calculated by: $R e=\frac{G \cdot D_{e}}{z}$.

If $H$ is the heat exchanger height, $s$ is the distance between surfaces in each channel, and $\dot{m}$ is the mass flow rate, we have:

$$
\begin{gathered}
G=\frac{\dot{m}}{H \cdot s} \\
D_{e}=\frac{2 H \cdot s}{H+s} \cong 2 s .
\end{gathered}
$$

As $H \gg s$ then the equivalent diameter is twice the distance between channels.

\subsection{Mechanical Design}

Spiral plate heat exchangers are built by rolling two parallel long sheets around a central bar to make a spiral shape. The free final edges of channels then will weld together to seal the end of channels. The distance between metal sheets is kept using studs that are welded to the sheets. The length of studs can vary from 5 to $25 \mathrm{~mm}$. hence, with respect to the mass flow rate, different distances between the sheets can be chosen during the design period. In each channel, hot or cold fluid path, secondary flows are developed that lead to better mixing and therefore heat transfer rate is increased and fouling is decreased. These heat exchangers are compact but their complicated construction procedure cause higher primary construction costs. Heat transfer surface area of these heat exchangers is from 0.5 to $500 \mathrm{~m}^{2}$. Maximum working pressure and temperature often restricted to 15 bar and 450 degrees Celsius, respectively. Applying new technologies may increase the maximum temperature up to 850 degrees Celsius. Using available equations and with respect to experimental requirements, a small LABsized model of the heat exchanger was made. Galvanized-Iron sheets were used. Properties of Galvanized-Iron are given in Table 1.

This type of sheet was used regarding its availability, acceptable price and good thermodynamic properties. The distances between two sheets were set to be $15 \mathrm{~mm}$ for one channel and $25 \mathrm{~mm}$ for another one. Figure 2 shows a view of the channels. The ends are welded. Also, the sides are closed by welding some sheets.

Figure 3 shows the completed heat exchanger.

Air pressure tests were done to check if there are some leakages. This is done by filling the heat exchanger up with air of the pressure of 2 bar gauge. After 12 hours, no change in the pressure was noticed. So we decided that the heat exchanger has no leakage.

\section{Table 1. Properties of galvanized-iron.}

\begin{tabular}{lc}
\hline$\rho$ & $7700-8100 \frac{\mathrm{kg}}{\mathrm{m}^{3}}$ \\
$k$ & $11.2-48.3 \frac{\mathrm{W}}{\mathrm{m} \cdot \mathrm{k}}$ \\
\hline & $(9-27) \times 10^{-6} \frac{1}{\mathrm{k}}$ \\
\hline
\end{tabular}



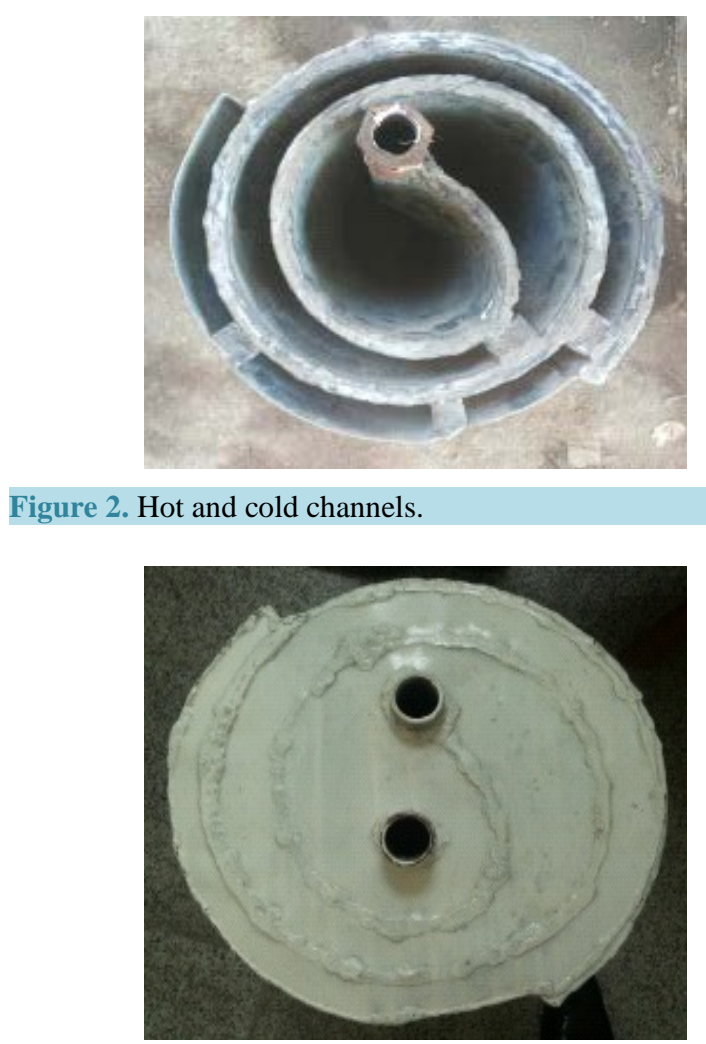

Figure 3. Completed heat exchanger.

\section{Simulation}

To check the usability of heat exchanger, a geometric model of it was made using Gambit software and then it was analyzed by means of Fluent software. Table 2 shows the flow parameters were used in Fluent.

To check the network independency, 3 networks including 16,000, 32,000, and 48,000 nodes were used. Considering the results, the network with 32,000 nodes opted to be used. In network making, we stressed the network near the highly changing areas such as entrances and walls. Figure 4 shows a view of the model.

Fluid is incompressible. The following boundary conditions were used: No slip condition on walls, temperature of the environment considered as $306 \mathrm{k}$. Heat transfer coefficient of air was set to be $h=5 \frac{\mathrm{W}}{\mathrm{m}^{2} \cdot \mathrm{k}}$. For internal walls we had: $-k \frac{\partial T}{\partial r}=h \Delta T$. For cold and hot outlet, the pressure was assumed to be atmospheric. Table 3 reviews some of the Fluent results.

Temperature distribution at surfaces of the distances of $0.1,0.2,0.3$, and $0.4 \mathrm{~m}$ from the entrance of the heat exchanger are shown in Figure 5. In analysis the worst case that is concurrent flow is considered.

As it is obvious from Figure 5, hot fluid is cooled as it flows through the heat exchanger, and cold fluid is warmed before leaving the heat exchanger. One can see from the figure that as the hot fluid passes the heat exchanger for each $0.1 \mathrm{~m}$ it advances its temperature drops about 1 degree Celsius and this amount is added to the temperature of the cold fluid.

To show a better view of the influence of the velocity on the Nusselt number, the Nusselt number versus velocity is shown in Figure 6.

This chart shows that for each velocity, Nusselt number of cold fluid is more than that of hot fluid. Also, for both fluids, Nusselt numbers increases as the velocity increases. This effect is the result of increasing the heat transfer coefficient by velocity. In this picture all the properties of two fluids are the same but the temperature. So, if the temperature of the cold fluid increases, and approaches that of hot fluid, its Nusselt number decreases.

Furthermore, mixing of the flow and the path of particles movement in heat exchanger were studied. Figure 7 


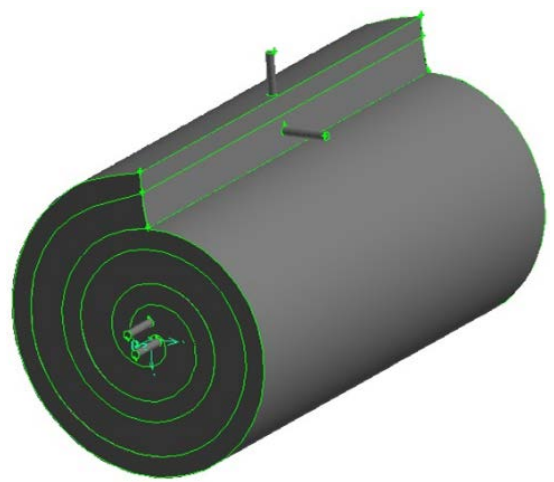

Figure 4. Heat exchanger model.
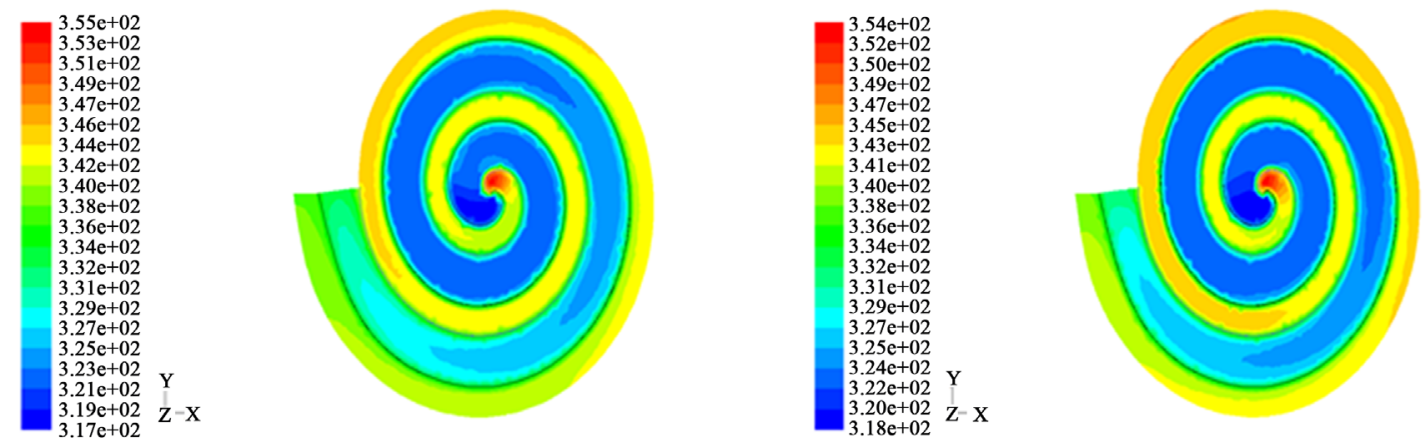

\begin{tabular}{|lr|rr}
\hline Contours of Static Temperature (k) & Jun 01, 2015 & Contours of Static Temperature (k) & Jun 01, 2015 \\
\hline
\end{tabular}

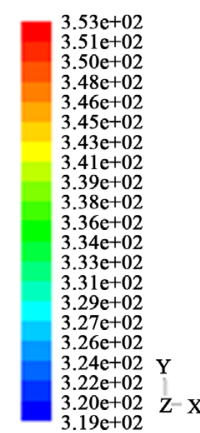

Contours of Static Temperature (k)

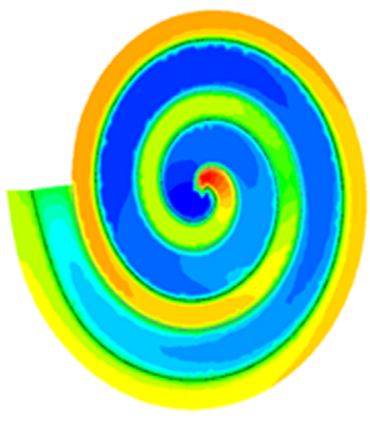

Jun 01, 2015

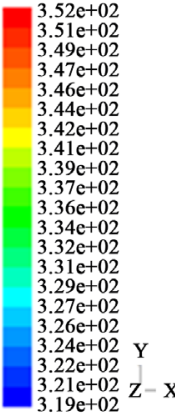

$3.21 \mathrm{e}+02$
$3.19 \mathrm{e}+02$

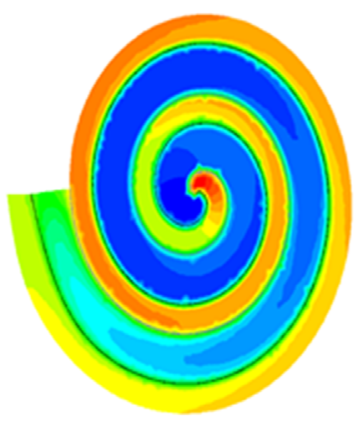

FLUENT 6.3

Figure 5. Several surfaces temperatures.

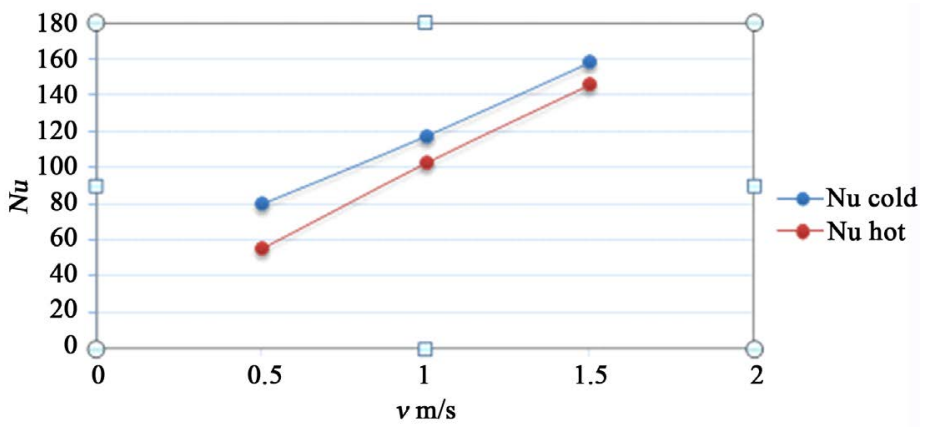

Figure 6. Nuselt vs velocity. 


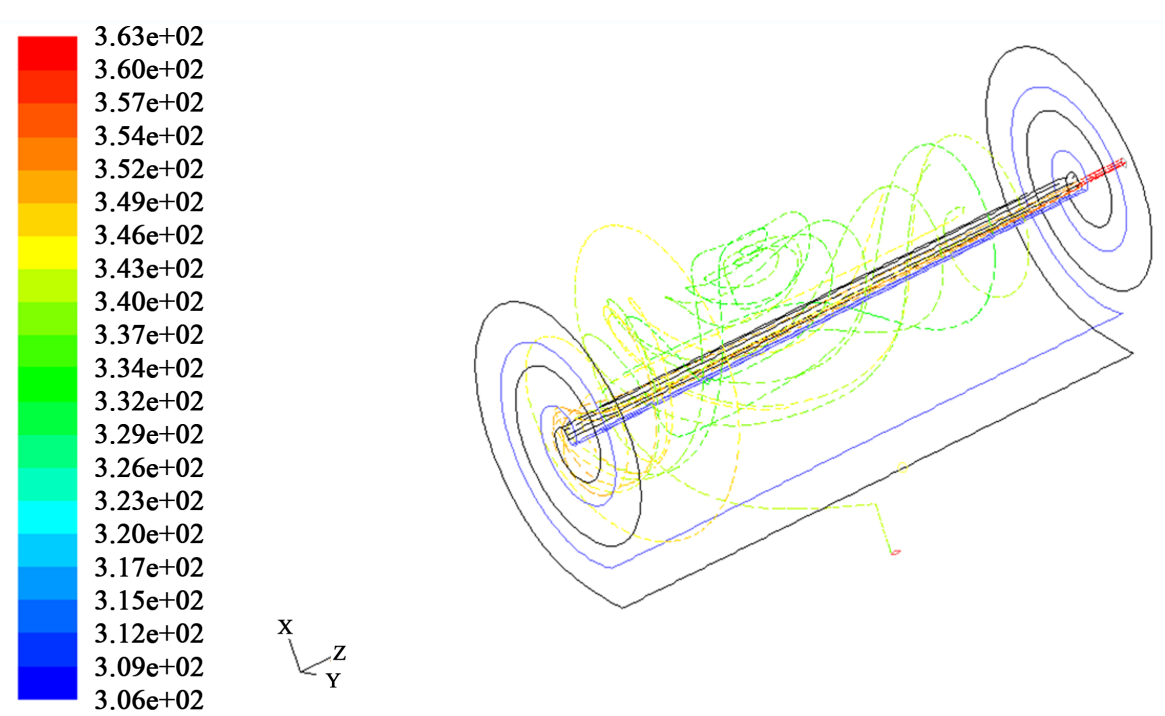

Pathlines Colored by Static Temperature (k)

Jun 01, 2015

FLUENT 6.3 (3d, dp, pbns, ske)

Figure 7. Particle movement path.

Table 2. Flow parameters for fluent.

\begin{tabular}{ccccc}
\hline Row & $V_{\text {in. hot }}\left(\frac{\mathrm{m}}{\mathrm{s}}\right)$ & $V_{\text {in. old }}\left(\frac{\mathrm{m}}{\mathrm{s}}\right)$ & $T_{\text {in. hot }}(\mathrm{k})$ & $T_{\text {in. cold }}(\mathrm{k})$ \\
\hline 1 & 0.5 & 0.5 & 353 & 301 \\
2 & 1 & 1 & 363 & 306 \\
3 & 1.5 & 1.5 & 373 & 311 \\
\hline
\end{tabular}

Table 3. Review of fluent simulation outlet.

\begin{tabular}{cccccccc}
\hline Row & $T_{\text {in. hot }}(\mathrm{k})$ & $T_{\text {in. hot }}(\mathrm{k})$ & $T_{\text {out. hot }}(\mathrm{k})$ & $T_{\text {out.cold }}(\mathrm{k})$ & $N u_{\text {hot }}$ & $N u_{\text {cold }}$ & $v\left(\frac{\mathrm{m}}{\mathrm{s}}\right)$ \\
\hline 1 & 353 & 301 & 331.46 & 322 & 130.28 & 143.12 & 1 \\
2 & 353 & 306 & 333.52 & 325.47 & 102.13 & 116.18 & 1 \\
3 & 353 & 311 & 335.59 & 328.40 & 80.97 & 94.22 & 1 \\
4 & 363 & 301 & 337.23 & 326.76 & 128.22 & 148.39 & 1 \\
5 & 363 & 306 & 339.37 & 334.50 & 102.25 & 116.42 & 1 \\
6 & 363 & 311 & 342.18 & 331.86 & 89.11 & 96.04 & 1 \\
7 & 373 & 306 & 345.10 & 333.89 & 103.09 & 118.06 & 1 \\
9 & 363 & 306 & 334.48 & 334.51 & 55.33 & 80.47 & 0.5 \\
9 & 363 & 306 & 342.12 & 326.87 & 146.50 & 158.98 & 1.5 \\
\hline
\end{tabular}

shows that the particles path is highly random and mixing is excellent. In the other hand, this leads to turbulent flow at speed much lower than that of straight path. Also, particles move in radial, axial and swirly paths.

\section{Conclusion}

In this work, a LAB-sized Spiral Plate Heat Exchanger was built. Galvanized-Iron was used because of its good 
thermodynamic properties, availability and acceptable price. No leakage was determined using air pressure test. This article studies the distribution of temperature and Nusselt number through Gambit and Fluent software. Heat transfer from hot fluid to cold fluid was done along the heat exchanger. The constructed heat exchanger will show good heat transfer behavior in both channels as can be interpreted from software outlets. Heat transfer is going to be very well along the heat exchanger. Fluid flow will become completely turbulent. Especial shape of the heat exchanger and secondary flows lead to random movement of the fluid particles in all directions so that axial, radial, and swirly movements exist together that mix the fluid very well and force the flow to be turbulent. Nusselt number magnitude is higher in the entrances because of the more temperature difference but it decreases as fluids go forward through the heat exchanger toward the exit points and as the temperature difference decreases. This is unanimous to the physics of heat transfer. Since the simulation of heat exchanger performance is possible, one can study the optimization of the heat exchanger. Velocity, Nusselt and temperature distribution predictions agree with the anticipated conditions. Regarding all the materials mentioned above, using this type of heat exchanger is economical and due to its all other advantages its usage is recommended.

\section{References}

[1] Kondahkar, G.E. and Kapatkat, V.N. (2012) Performance Analysis of Spiral Tube Heat Exchanger Used in Oil Extraction System. International Journal of Modern Engineering Research, 2, 930-936.

[2] Naphon, P. (2007) Thermal Performance and Pressure Drop of the Helical-Coil Heat Exchangers with and without Helically Crimped Fins. International Communications in Heat and Mass Transfer, 34, 321-330. http://dx.doi.org/10.1016/j.icheatmasstransfer.2006.11.009

[3] Deshpande, P.M. and Dwande, S. (2012) Study of Hydrodynamics of Horizontal Spiral Coil Tube. International Journal of Advanced Engineering Research and Studies, 1, 112-114.

[4] Tandale, M.S. and Joshi, S.M. (2008) Design of Heat Exchanger for Waste Heat Recovery from Producer Gas. Proceedings of the International Conference on Heat and Mass Transfer, Acapulco, January 2008, 1790-2769.

[5] Ke, Y., Qi, G.P., Cay, S.Y. and Bo, B.W. (2010) Mathematical Analysis of Transverse Vibration of Conical Spiral Tube Bundle with External Fluid Flow. Journal of Hydrodynamics, 22, 816-822. http://dx.doi.org/10.1016/S1001-6058(09)60121-9

[6] Nueza, M.P., Polley, G.T., Davalos, L.C. and Rodriguez, G.M. (2007) Design Approach for Spiral Heat Exchanges. Institution of Chemical Engineering, 85, 322-327.

[7] Minton, P.E. (1971) Designing Spiral Tube Heat Exchangers. Process Heat Exchange, 136-144.

[8] Mori, Y. and Nakayama, W. (1965) Study on Forced Convective Heat Transfer in Curved Pipes (1st Report, Laminar Region). International Journal of Heat and Mass Transfer, 8, 67-82. http://dx.doi.org/10.1016/0017-9310(65)90098-0

[9] Kalb, C.E. and Seader, J.D. (1972) Heat and Mass Transfer Phenomena for Viscous Flow in Curved Circular Tubes. International Journal of Heat and Mass Transfer, 15, 801-817. http://dx.doi.org/10.1016/0017-9310(72)90122-6 